\title{
HEAT TRANSFER ENHANCEMENT OF HE II CO-CURRENT TWO-PHASE FLOW IN THE PRESENCE OF ATOMISATION
}

\author{
B. Rousset ${ }^{1}$, P. Thibault ${ }^{1}$, S. Perraud ${ }^{1} /^{2}$, L. Puech ${ }^{2}$, P. E. Wolf ${ }^{2}$, R. van Weelderen ${ }^{3}$
}

Previous experiments performed on HeII co-current two-phase flow at CEA Grenoble have shown the existence of a transition from stratified two-phase flow to droplet mist flow at high vapour velocities. The realisation of a new refrigerator/liquefier able to produce up to $20 \mathrm{~g} / \mathrm{s}$ of single phase superfluid helium at $1.8 \mathrm{~K}$ (instead of $7 \mathrm{~g} / \mathrm{s}$ previously) was achieved. Benefit was taken of the necessary junction between the existent test line and the refrigerator to introduce some new instrumentation [1]. Results of preliminary experiments performed on this new configuration are given. The response of liquid level and vapour density on droplet flow is presented. First results on pressure drop obtained for a total mass flow rate of $15 \mathrm{~g} / \mathrm{s}$ are also presented. Finally, the use of various capacitive level gauges glued at different azimutal positions along the inner pipe give access to the perimeter wetted by a continuous thin liquid film.

1 CEA-Grenoble/DRFMC/SBT, Grenoble, France

2 CNRS/CRTBT, Grenoble, France

3 CERN, Accelerator Technology Department, Geneva, Switzerland

Presented at the 20th International Cryogenic Engineering Conference (ICEC20)

11-14 May 2004, Beijing, China

Administrative Secretariat

AT Department

CERN

CH - 1211 Geneva 23
Geneva, Switzerland

22 September 2004 


\title{
Heat Transfer Enhancement of He II Co-current Two-phase Flow in The Presence of Atomisation
}

\author{
B. Rousset*, P. Thibault**, S. Perraud*/**, L. Puech**, P. E. Wolf**, R. van Weelderen*** \\ * CEA-Grenoble/DRFMC/SBT, 17 rue des Martyrs, 38054 Grenoble Cedex 09, France \\ ** CNRS /CRTBT, 17 rue des Martyrs, 38054 Grenoble Cedex 09, France \\ *** Accelerator Technology Department, CERN, 1211, Geneva, Switzerland
}

\begin{abstract}
Previous experiments performed on HeII co-current two-phase flow at CEAGrenoble have shown the existence of a transition from stratified two-phase flow to droplet mist flow at high vapour velocities. The realisation of a new refrigerator/liquefier able to produce up to $20 \mathrm{~g} / \mathrm{s}$ of single phase superfluid helium at $1.8 \mathrm{~K}$ (instead of $7 \mathrm{~g} / \mathrm{s}$ previously) was achieved. Benefit was taken of the necessary junction between the existent test line and the refrigerator to introduce some new instrumentation [1]. Results of preliminary experiments performed on this new configuration are given. The response of liquid level and vapour density on droplet flow is presented. First results on pressure drop obtained for a total mass flow rate of $15 \mathrm{~g} / \mathrm{s}$ are also presented. Finally, the use of various capacitive level gauges glued at different azimutal positions along the inner pipe give access to the perimeter wetted by a continuous thin liquid film.
\end{abstract}

\section{INTRODUCTION}

Large size superconductive magnets are generally made of $\mathrm{NbTi}$ or of $\mathrm{Nb} 3 \mathrm{Sn}$ and require to be operated at liquid helium temperature. Moreover, in the case of high magnetic fields, it may be necessary to decrease the temperature below $2.2 \mathrm{~K}$ and thus to enter the field of superfluid helium (e.g. the future LHC at CERN or the tokamak Tore Supra at CEA). To avoid the presence of vapour in contact with the magnets, He II around the magnets will have to be subcooled (i.e. maintained with a pressure higher than its saturated vapour pressure). This subcooling will be done through a heat exchanger separating the pressurized He II and the saturated He II (i.e. the cold source). The safe operation of the magnet depends on the effectiveness of this heat exchanger. In the case of LHC, the system studied by CEA/SBT is made of a heat exchanger pipe traversing right through the magnets[2]. The magnets will be immersed in a static bath at 1 Bar of pressurized superfluid helium. The heat exchanger pipe is cooled by a He II two-phase flow, the tube being almost entirely filled with liquid at a magnet string inlet and being dry at exit (heat losses collected along the flow evaporating the liquid). Previous experiments consisted of a two phase cocurrent stratified flow through a $40 \mathrm{~mm}$ inner diameter, $10 \mathrm{~m}$ long tube, with a descending slope ranging between 0 and 1.4\%. Studies highlighted an improvement of heat exchange at high vapour velocities, while at the same time only a small fraction of liquid remains present in the tube. This excess of heat exchange appears simultaneously with the presence of droplets within the vapour phase. One can think that the spray generated above the level of the free surface will deposit on the wall and will strongly increase heat exchange. After deposition, the drops can flow and contribute to a liquid film.

Due to the limitation in available mass flow $(7 \mathrm{~g} / \mathrm{s})$, the range in vapour velocities was limited, in particular for temperatures higher than $2 \mathrm{~K}$, were velocity values higher than $8 \mathrm{~m} / \mathrm{s}$ could not be achieved. For the same reason, it was not possible to have both high vapour velocities and sufficient residual liquid mass flow, preventing the investigation of the influence of liquid level on droplet flow.

In order to overcome these limitations, the use of a new refrigerator/liquefier able to produce up to $20 \mathrm{~g} / \mathrm{s}$ of single phase superfluid helium at $1.8 \mathrm{~K}$ was scheduled. Other improvements in this new 
configuration include the possibility to obtain steady state two-phase flow regimes from very low vapour quality up to pure vapour. Preliminary results are presented hereafter.

\section{EXPERIMENTAL FACILITY AND INSTRUMENTATION}

The previous cryoloop experiment (figure 1) has been connected to a new refrigerator able to remove up to $400 \mathrm{Watt}$ at $1.8 \mathrm{~K}$. From inlet to outlet, the test line mainly consists of series of thermometers, a heat exchange box (from which the inner wetted perimeter of the tube is calculated), a first capacitive level gauge device (see figure 2a), and two optical sectors.

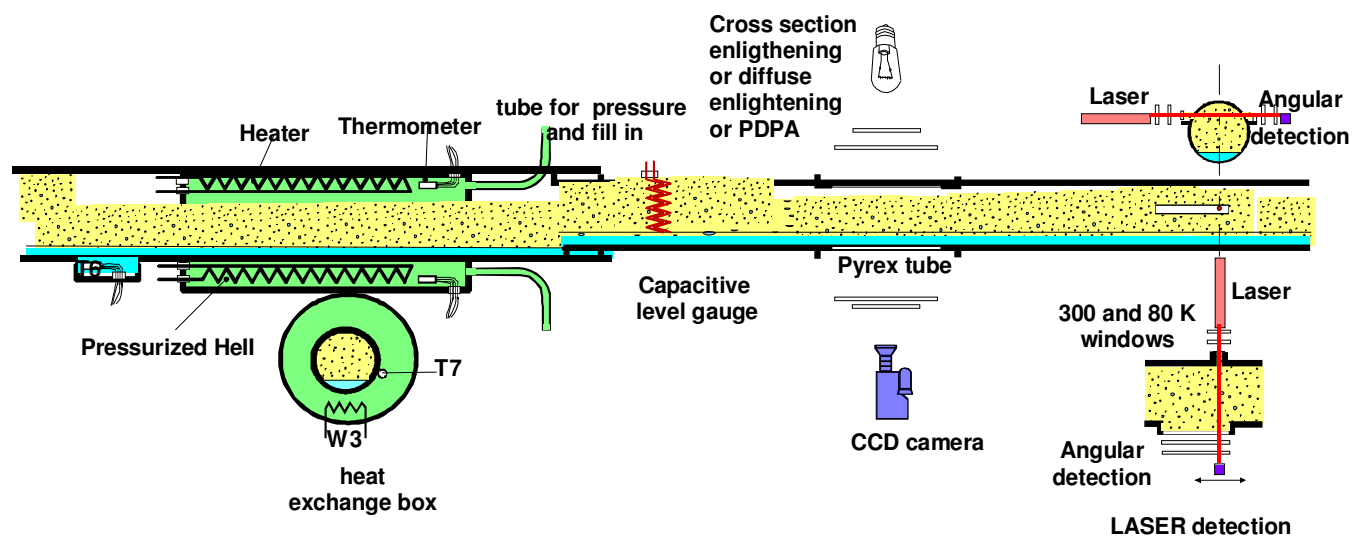

Figure 1. Scheme of the cryoloop instrumentation

A new instrumental sector including a second capacitive level gauge of different gaps and capacitive flags was also introduced in the test line (figure $2 b$ ). Description and fabrication of the capacitive sensors were given elsewhere[3]. The capacitive response of this sensor depends on the wet surface and on the thickness of the liquid film covering the wet surface. Figure $2 \mathrm{c}$ shows this dependence for various gaps between electrodes. Calculations were performed using the ANSYS code. In first approximation, once the liquid thickness of the wet part is higher than the gap between the two electrodes, the measurement directly indicates the wet area.

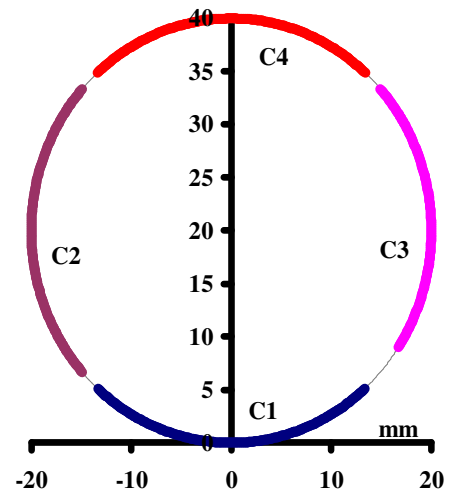

Figure 2a Position of the capacitive gauges of $100 \mu \mathrm{m}$ gap inside the first sector.

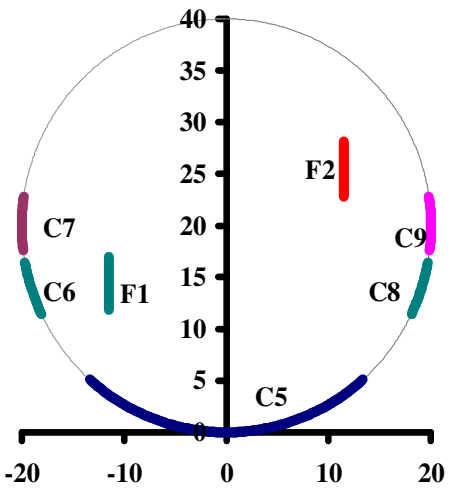

Figure $2 \mathrm{~b}$ C5 is identical to $\mathrm{C} 1, \mathrm{C} 6$ and $\mathrm{C} 7$ have a $30 \mu \mathrm{m}$ gap and $\mathrm{C} 8, \mathrm{C} 9, \mathrm{~F} 1$ and $\mathrm{F} 2$ have a $50 \mu \mathrm{m}$ gap. $\mathrm{F} 1$ and $\mathrm{F} 2$ are placed in a separated sector.

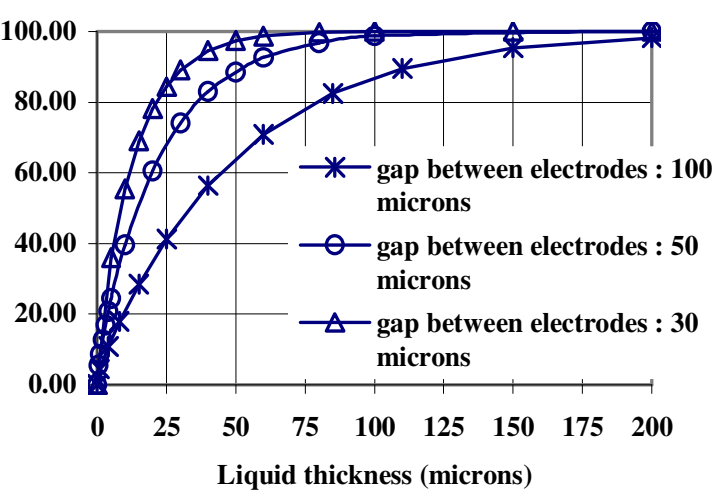

Figure 2c Relative variation (in \%) of the capacitance with the thickness of a uniform liquid helium film

The response of these sensors will be presented in percentage, $0 \%$ corresponding to the dry situation and $100 \%$ to the situation where the sensor is wetted over its whole surface with a film thicker than the gap between electrodes. 


\section{RESULTS AND ANALYSIS}

All measurements presented here are acquired at the end of a $11 \mathrm{~m}$ long tube (40 mm I.D.) for a $0.6 \%$ slope. Heat losses along this straight tube are estimated to $10 \mathrm{Watt}$.

Heat transfer results

Typical accuracy of capacitive sensors can be appreciated from the comparison between $\mathrm{C} 1$ and $\mathrm{C} 5$ (figure 3); these two sensors being identical and located at the same altitude inside the pipe.

As already mentioned and explained[4], wall heat transfer is directly proportional to the inner wetted perimeter of the tube. Heat transfer is improved at high vapour velocities (figure 4). However, this tends to be reduced when heat flux increases, which can be explained by a dry out of the upper part of the pipe.

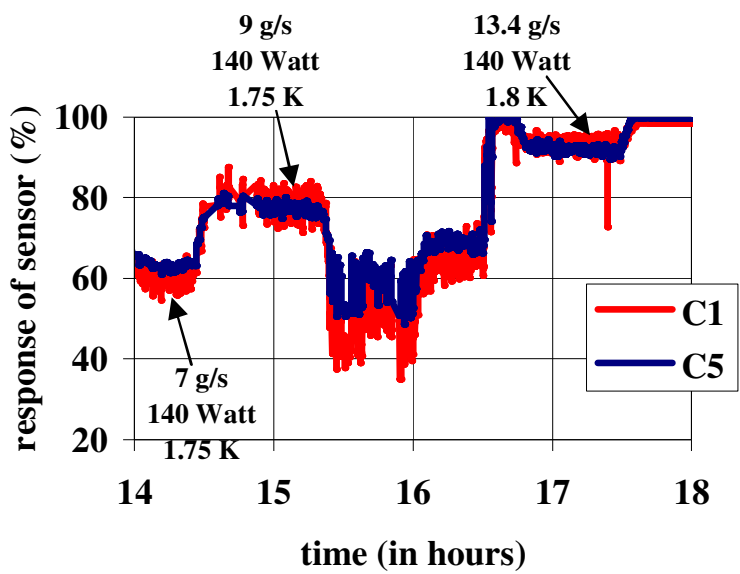

figure 3 Perimeter wetted by the liquid at the bottom of the tube

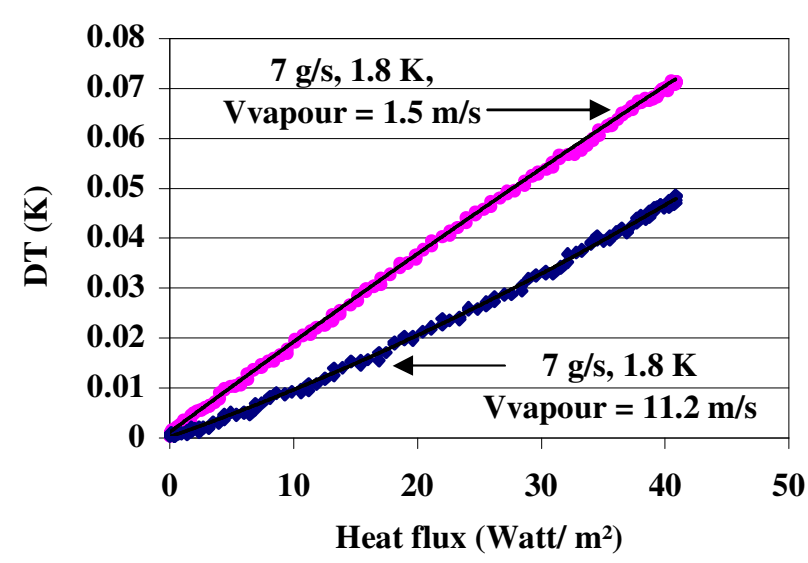

figure 4 Increase in temperature in the pressurized bath

Table 1 Summary of experimental results. $\mathrm{m}$ is the total mass flow (in $10^{-3} \mathrm{~kg} / \mathrm{s}$ ), W the inlet power injected (in Watt), $\mathrm{T}$ the temperature (in Kelvin) and $\mathrm{H}$ the heat transfer measured in the heat exchange box (measured for a heat flux of $40 \mathrm{Watt} / \mathrm{m}^{2}$ ) converted in wetted perimeter (in \%).

\begin{tabular}{|c|c|c|c|c|c|c|c|c|c|c|c|c|c|c|}
\hline line & $\mathrm{m}$ & $\mathrm{W}$ & $\mathrm{T}$ & $\mathrm{H}$ & $\mathrm{C} 1$ & $\mathrm{C} 2$ & $\mathrm{C} 3$ & $\mathrm{C} 4$ & $\mathrm{C} 6$ & $\mathrm{C} 7$ & $\mathrm{C} 8$ & $\mathrm{C} 9$ & $\mathrm{~F} 1$ & $\mathrm{~F} 2$ \\
\hline 1 & 7 & 140 & 1.75 & 57.3 & 60 & 3.6 & 3 & 0.3 & 20.5 & 15.5 & 14.7 & 11.7 & 6.8 & 5.1 \\
\hline 2 & 9 & 140 & 1.75 & 64.3 & 79 & 5.1 & 4.8 & 0.6 & 24.6 & 18.9 & 17.7 & 14.3 & 8.6 & 7.4 \\
\hline 3 & 13.4 & 140 & 1.80 & 66.5 & 92 & 10 & 5.6 & 0.9 & 28 & 21.1 & 20.0 & 15.4 & 9.4 & 8.0 \\
\hline 4 & 15.3 & 80 & 1.84 & 37 & 100 & 11.4 & 2.1 & 1.6 & 1 & 3 & $\mathrm{X}$ & $\mathrm{X}$ & 2.4 & 1 \\
\hline 5 & 15.3 & 174 & 1.84 & 73 & 95 & 13.4 & 8 & 3 & 29 & 24 & $\mathrm{X}$ & $\mathrm{X}$ & 10.0 & 8.2 \\
\hline 6 & 15.3 & 200 & 1.84 & 71 & 90 & 11.6 & 7.8 & 3.4 & 32 & 24 & $\mathrm{X}$ & $\mathrm{X}$ & 10.2 & 9.0 \\
\hline 7 & 15.3 & 280 & 1.84 & 71 & 45 & 5.3 & 5 & 3.2 & 22.5 & 17 & $\mathrm{X}$ & $\mathrm{X}$ & 10.5 & 10.5 \\
\hline
\end{tabular}

Comparison between lines 1 to 3 of table 1 gives access to the influence of free surface level (given by $\mathrm{C} 1$ ). For approximately the same vapour velocity, values of capacitive sensors increases as the liquid level increases. Comparison between $\mathrm{C} 6$ and $\mathrm{C} 8$ (located at the same altitude), indicates that sensors are covered by a layer of liquid thinner than $30 \mu \mathrm{m}(\mathrm{C} 6>\mathrm{C} 8$ and $\mathrm{C} 6<100 \%)$. Comparison between $\mathrm{F} 1$ and $\mathrm{C} 8$ indicates that liquid is probably flowing down to the free surface, $\mathrm{C} 8$ being also partly covered with liquid at its upper part.

Looking at the values of F1 and F2 for all the lines, one can have an estimate of the mist stratification. Mist was always found stratified except for line 7, this latter corresponding to the maximum velocity and the minimum free surface level obtained. 


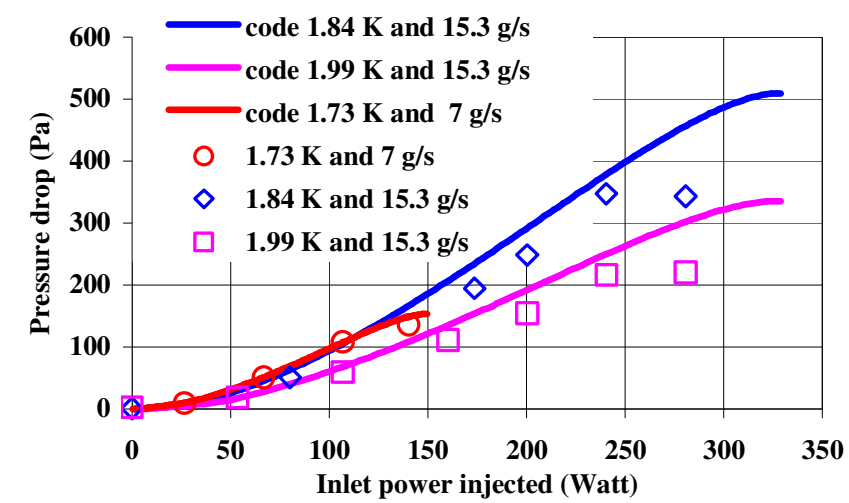

figure 5a Comparison between previous code and experiments

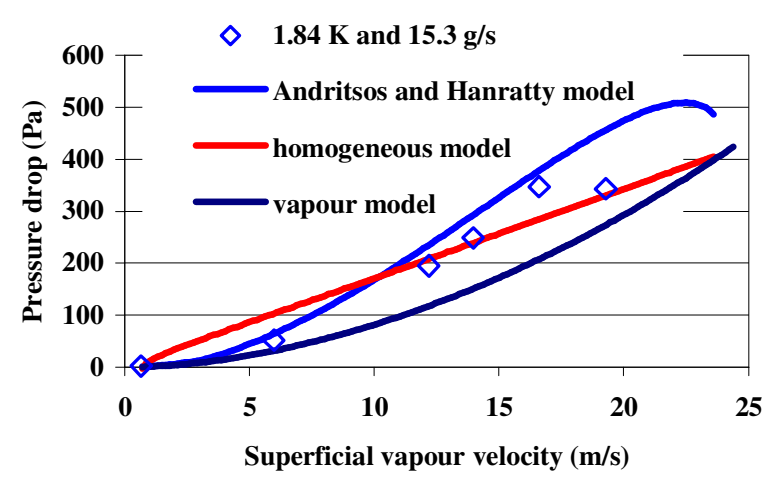

figure 5b Comparison between various models and experiments performed at high velocities

Previous experiments were used to validate a model using the Andritsos Hanratty[5] correlation in the range of 1 to $7 \mathrm{~g} / \mathrm{s}$ and 1.8 to $2 \mathrm{~K}$. We check here its validity for a wider range of mass flow and vapour velocities (figure 5a). Furthermore, our new test station enables experiments with a larger void fraction. It was found that for the largest void fraction (i.e. the largest power injected), discrepancies with the model appear. Comparison with various models (figure 5b) suggests the use of a homogeneous model in this last case, which is compatible with the low free surface level observed.

\section{CONCLUSION}

He II two-phase flow measurements were performed at a mass flow ranging from 7 to $15 \mathrm{~g} / \mathrm{s}$ and a temperature ranging from 1.8 to $2 \mathrm{~K}$. Improvement of wall heat transfer at high vapour velocities was confirmed, with a corresponding wetted inner tube value as high as $70 \%$ for the highest velocities. Droplet deposition on wall forms a thin liquid film. Film thickness depends on altitude and velocities. Above the free surface, the mist of droplets is stratified, with almost no droplets at the top of the tube. Furthermore liquid film is falling along the wall and tends to increase its thickness until it reaches the free surface. For the highest velocities, the mist was found more homogeneous.

Pressure losses were found in good agreement with our previous code derived from the Andritsos and Hanratty model[5] except for the highest vapour velocity corresponding to the largest void fraction. In that case, the major fraction of liquid phase may flows as a spray and a homogeneous model would be more convenient.

\section{ACKNOLEDGMENTS}

Authors would take here the opportunity to thanks Roser Vallcorba for its works on ANSYS and the SBT/GRTH technician team for the assembly and test of all the components of the test loop.

\section{REFERENCES}

1. Thibault P. et al., Description of a new experiment to explore HeII two phase flow behavior at high mass flow rate International Cryogenics Engineering Conference 19 Grenoble, France(2002), 825-828

2. Lebrun P. et al., Cooling String of Superconducting Devices below $2 \mathrm{~K}$ : the Helium II Bayonet Heat Exchanger Advances in Cryogenics Engineering (1998) 43 419-426

3. Thibault P. et al., Probing the Wetted Perimeter in a Pipe-Flow Experiment Using a Capacitive Sensor, Advances in Cryogenics Engineering (2002) 47 1683-1690

4. Rousset B. et al., HeII two phase flow in an inclinable $22 \mathrm{~m}$ long line, Advances in Cryogenics Engineering (2000), 45 $1009-1016$

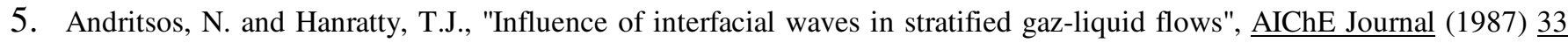
444-454 